\title{
Bandwidth Enhancement and Radiation Characteristics Improvement of Triangular Dielectric Resonator Antenna
}

\author{
Mehdi Ghorbani $^{1}$, Mohsen Khalily ${ }^{2}$, Habib Ghorbaninejad ${ }^{1}$, Pei Xiao ${ }^{2}$, Rahim Tafazolli ${ }^{2}$ \\ ${ }^{1}$ Deptartment of electrical engineering, University of Guilan, Rasht, Iran \\ ${ }^{2}$ Institute for Communication Systems (ICS), Home of the 5 G innovation center (5GIC), University of Surrey, U.K. \\ ghorbani.me@gmail.com
}

\begin{abstract}
In this paper, an ultra-wideband, Dielectric Resonator Antenna (DRA) has been proposed. The proposed antenna is based on isosceles triangular DRA (TDRA), which is fed from the base side using a $50 \Omega$ probe. For bandwidth enhancement and radiation characteristics improvement, a partially cylindrical-shape hole is etched from its base side which approached probe feed to the center of TDRA. The dielectric resonator (DR) is located over an extended conducting ground plane. This technique has significantly enhanced antennas bandwidth from $48.8 \%$ to $80 \%(5.29-12.35 \mathrm{GHz})$, while the biggest problem was radiation characteristics. The basis antenna possesses negative gain in a wide range of bandwidth from $7.5 \mathrm{GHz}$ to $10.5 \mathrm{GHz}$ down to $-13.8 \mathrm{dBi}$. Using this technique improve antenna gain over $1.6 \mathrm{dBi}$ for whole bandwidth, while peak gain is $7.2 \mathrm{dBi}$.
\end{abstract}

Keywords-Dielectric resonator Antenna (DRA), Triangular DRA, Wideband, probe feed

\section{INTRODUCTION}

DRA antennas features include low cost, low loss, small size, and high radiation efficiency. Therefore, they are favorable subject for antenna designers. On the other hand, UWB antennas have been widely used in radars, navigation, GPS, biomedical systems, mobile satellite communications, the direct broadcast systems, telemetry etc. Variety shapes of DRAs like rectangular and cylindrical DRA antennas have been studied, and various techniques have been used to improve the antenna parameters.

One of the most important features of the antenna is impedance bandwidth. Antenna bandwidth can be widened through feed or resonator. Tapered strip excitation from a side of the dielectric resonator [1] and extended microstrip feed in the proximity of DR [2] significantly improved antenna bandwidth. In [3], DRA feed was modified base on the concept of hybrid antenna. Trapezoidal DRA [4] is proved as a potential structure for wideband applications. Changing the structure of Square or rectangular DRA also can improve the antenna impedance bandwidth. Loading inclined slits on diagonal of square DRA [5], and several printed rectangular loops on Ring Rectangular DRA [6] are clear illustrations of this importance.

The TDRA is another research topics which have been taken into consideration in recent years, due to offering a wide impedance bandwidth. A $30^{\circ}-75^{\circ}-75^{\circ}$ TDRA which was fed by a probe has a wideband feature [7]-[8]. It also was discovered that excitation of TDRA form the center of the base side result to wider bandwidth. In [9], equilateral TDRA with a specific shape of CPW loop feed had been designed.

Another useful techniques, which has widely been used, are multiple shapes next to or in front of each other and stacked configuration. Three TDRA [10] and four TDRA with same [11] and different permittivity [12] were investigated in which all TDRAs were fed from the apex. Stacked form of TDRAs [13] and different scales of up and down sections [14] were also reported for wideband applications. In [15] arrays of a circular-shape slots are drilled uniformly, it improved bandwidth by letting down the quality factor.

In this paper, an ultra-wideband TDRA has been designed, which includes worthwhile results in comparison with relevant recent works. The proposed antenna is a isosceles TDRA antenna, which is located on the extended conducting ground plane and is fed by a coaxial probe from base of triangle. The basis TDRA suffer from inappropriate return loss as well as negative gain on approximately $3 \mathrm{GHz}$. A partially cylindrical-shape hole is etched from the base side of the TDRA, The proposed structure realized wideband and good radiation characteristics in the whole antenna bandwidth.

\section{DESIGN AND SIMULATION}

\section{A. The Proposed Antenna Structure}

Fig. 1(A) and 1(B) show the 3D view and top view of the proposed antenna, respectively. The proposed antenna composed of a triangular dielectric that is mounted on a square-shaped conductive ground plane, and small circle is removed from the base side of the TDRA. The proposed antenna is fed by a $50 \Omega$ coaxial probe which it is placed inside of the circle so that it touches the lateral wall of hole. Conducting ground plane dimensions are assumed $140 \times 140$ $\mathrm{mm}^{2}$, and the dielectric material with permittivity of 10 is used. The proposed antenna dimensions includes triangle median $(\mathrm{a}=19 \mathrm{~mm})$, and the small side $(\mathrm{b}=9 \mathrm{~mm})$ and height of $\mathrm{h}=19 \mathrm{~mm}$. The center of a $3.0 \mathrm{~mm}$ circle has been closed to the center of TDRA in the distance of $1.5 \mathrm{~mm}$. The TDRA is fed with a $50 \Omega$ coaxial probe which is placed inside, and touches the innermost surface of the circle. Probe height is considered $h_{p}=7 \mathrm{~mm}$. 

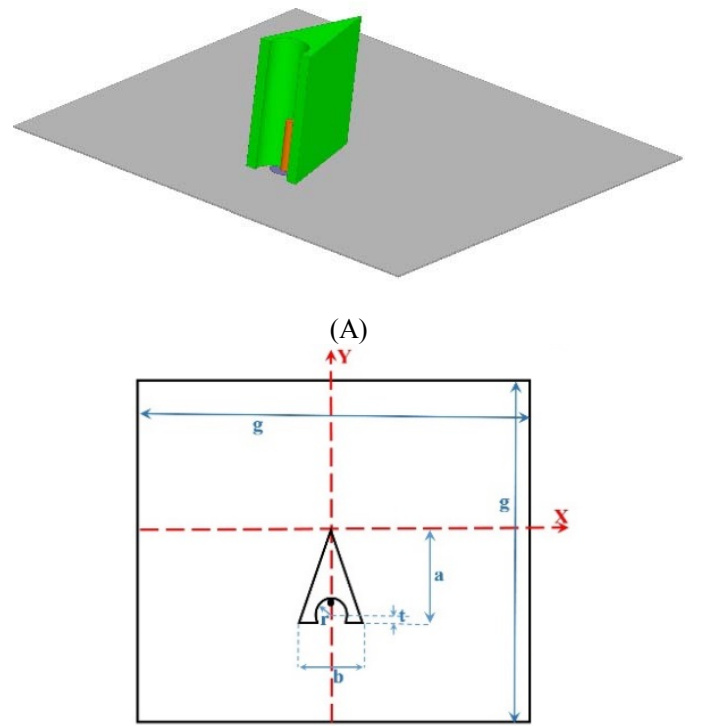

(B)

Fig. 1. A. 3D view and B. top view of the proposed antenna configuration

\section{B. Design Steps}

Isosceles base size: Figure 2 (A) and (B) respectively show the gain and the return loss of the proposed antenna in the term of triangle base. The figures show that decreasing the base size improves the antenna bandwidth. The antenna bandwidths are respectively $50.5 \%, 48.8 \%$, and $44.5 \%$ for the base size of 8,9 , and $10 \mathrm{~mm}$. The purpose is bandwidth improvement in higher frequencies, but the gain in the frequency range of $7.5 \mathrm{GHz}$ to $10.5 \mathrm{GHz}$ is less than $0 \mathrm{dBi}$. Therefore, gain improvement is much more critical than bandwidth. On the whole, $b=9 \mathrm{~mm}$ is chosen.
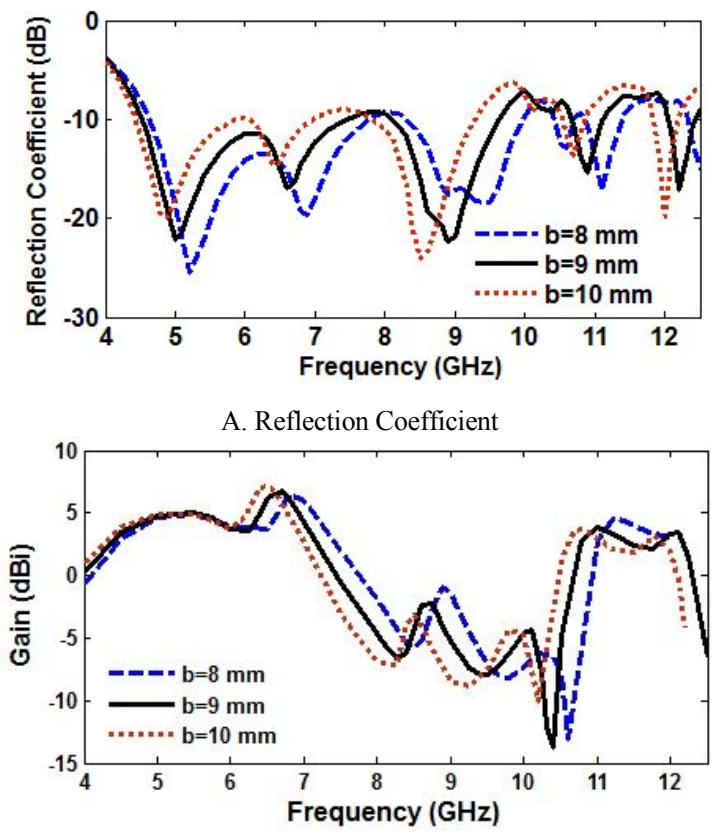

B. Gain

Fig. 2. A. Return loss and B. Gain of the proposed antenna in accordance with base triangle

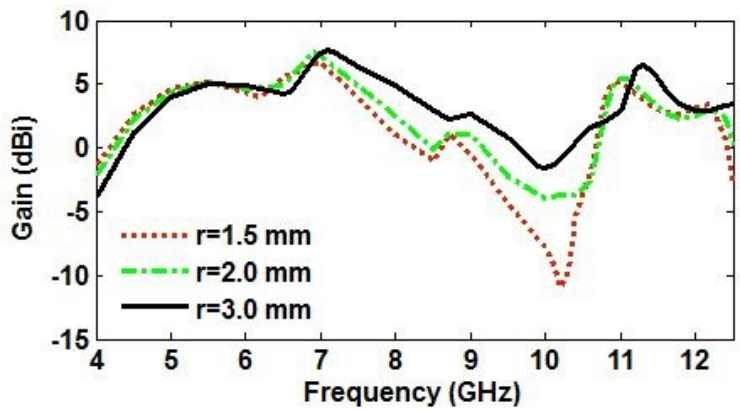

A. Gain

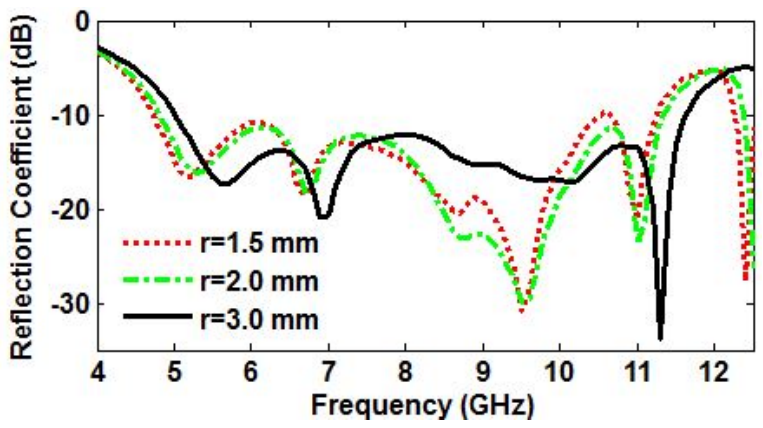

B. Reflection Coefficient

Fig. 3. A. Gain and B. Return loss of the proposed antenna in accordance with circle diameter

Removed circle diameter (r): At the next step of design procedure, a circle is removed from triangle cross-section. At this step, the center of the circle is assumed to locate on the base side of the triangle. Figures $3 \mathrm{~A}, 3 \mathrm{~B}$ show the gain and the return loss in accordance with the circle radius.

These figures depict that increasing of the circle diameter improves the gain chart significantly, particularly around 10 $\mathrm{GHz}$. It also improves the return loss. Figure 3 (A), and (B) shows that increasing of the circle diameter improves the gain chart significantly, and return loss chart slightly, therefore $\mathrm{r}=3.0 \mathrm{~mm}$ is chosen as the best value. This technique improves the bandwidth of the proposed antenna from $48.8 \%$ to $80.0 \%$, and minimum gain is improved from $-13.8 \mathrm{dBi}$ to $-1.6 \mathrm{dBi}$, but still $700 \mathrm{MHz}$ of the bandwidth has the gain of less than $0 \mathrm{dBi}$. It should be mentioned that the higher values of $r$ decreases the distance between inside wall of the hole and triangle sides and attenuate the side thickness of the hole. Consequently, it prevents next step.

Movement of circle center to inside the triangle ( $t)$ : At this step, the circle center that at previous step was assumed on the base side, is closed to the inside of the triangle $(t)$. The parameter of $t$ is the distance between the center of circle and the base side of triangle (see figure $1(\mathrm{~B})$ ).

Figures 3 (A) and (B) show the return loss and the gain of the proposed antenna in term of the parameter of $t$. Figure 3 (B) depicts that increasing of the parameter of $t$ improve the gain chart, but figure 3 (A) illustrates that increasing of this parameter improve the return loss in lower frequencies and deteriorates it in higher frequencies. For the case of $\mathrm{t}=2.0 \mathrm{~mm}$, the return loss chart in the range of $10.0 \mathrm{GHz}$ to $11.1 \mathrm{GHz}$ suffer from inappropriate return loss, therefore $\mathrm{t}=1.5 \mathrm{~mm}$ is chosen as the best value for this step of parametric study. 


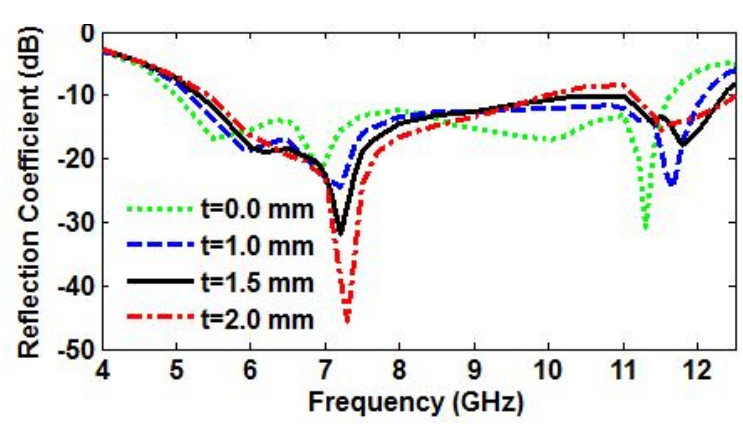

A. Return loss

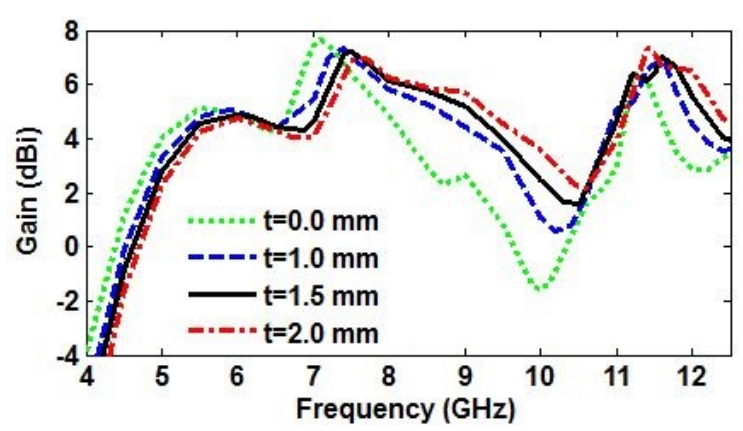

B. Gain

Fig. 4. A. Return loss and B. Gain of the proposed antenna in the term of distance between the circle center and the base side of triangle

The final dimensions of the proposed antenna are shown in table 1.

TABLE I. FINAL DIMENSIONS OF PROPOSED ANTENNA

\begin{tabular}{ccccccc}
\hline Parameter & $\mathbf{g}$ & $\mathbf{a}$ & $\mathbf{b}$ & $\mathbf{h}$ & $\mathbf{r}$ & $\mathbf{t}$ \\
\hline Value & 140 & 19 & 9 & 19 & 3 & 1.5 \\
\hline (all dimension in $\mathrm{mm})$ & & & & &
\end{tabular}

\section{Results}

The proposed antenna has been simulated and optimized using HFSS, and good characteristic is achieved. The impedance bandwidth of $80.0 \%$ from $5.29 \mathrm{GHz}$ to $12.35 \mathrm{GHz}$ is achieved with a suitable return loss ( ). The gain variation is from $1.6 \mathrm{dBi}$ to $7.2 \mathrm{dBi}$, and the mean gain is $4.5 \mathrm{~dB}$. Figure 5 shows the E-plane and H-plane of the proposed antenna at 6.0, 9.0 and $12.0 \mathrm{GHz}$. These figures show that the proposed antenna has a stable radiation pattern at all of the bandwidth. Side lobe and back lobe level at $6.0 \mathrm{GHz}$ are $-18 \mathrm{~dB}$, at 9.0 $\mathrm{GHz}$ are $-17 \mathrm{dBi}$ and $-18 \mathrm{dBi}$, and at $12.0 \mathrm{GHz}$ are $-14 \mathrm{dBi}$ and $-18 \mathrm{dBi}$, respectively.

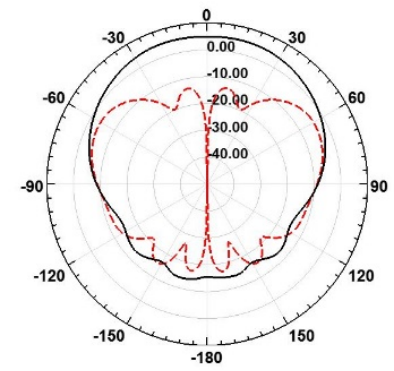

(A)

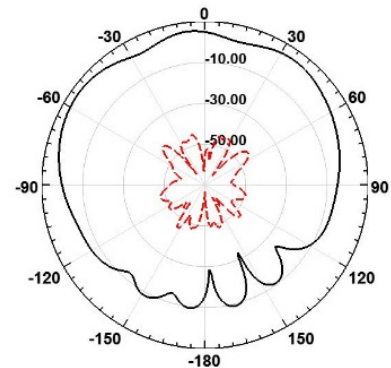

(B)

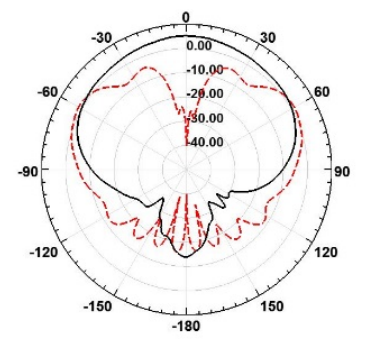

(C)

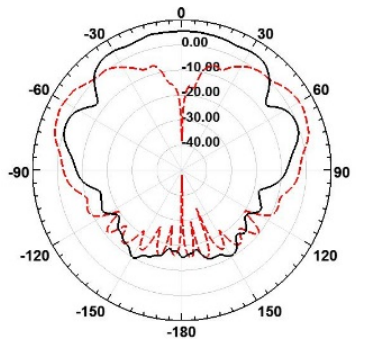

(E)

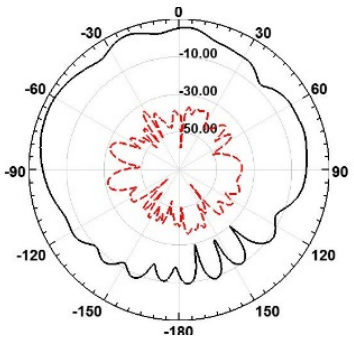

(D)

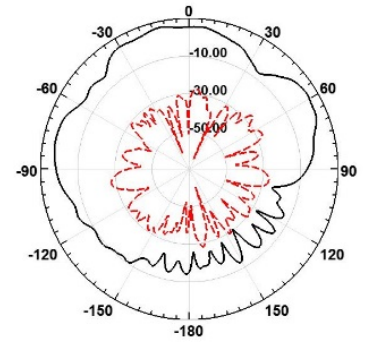

(F)
Fig. 5. A,C, and E: E-plane; B, D, and F: H-plane of the proposed antenna respectively at 6,9 , and $12 \mathrm{GHz}$

It was reported that for a specified resonant frequency and Dielectric resonator height, TDRAs offers the smaller area in comparison with cylindrical and rectangular antenna. Also, it was proved that just $\mathrm{TMz}$ modes are excited in TDRA antennas. This resonant frequency for equilateral TDRA can be written as follows [10]:

$$
f_{m n}=\frac{c}{2 \sqrt{\varepsilon_{r}}}\left[\left(\frac{4}{3 a}\right)^{2}\left(m^{2}+m n+n^{2}\right)+\left(\frac{k}{2 h}\right)^{2}\right]^{\frac{1}{2}}
$$

Where $\mathrm{c}$ is light speed in free space, is relative permittivity, a is side length, and $h$ is DRA height.

Figures 6 (A), (B), (C), and (D) show the internal electric field of TDRA at respectively $6.2 \mathrm{GHz}, 7.2 \mathrm{GHz}, 11.4 \mathrm{GHz}$, and $11.8 \mathrm{GHz}$. From the figures, it can be founded that these resonant frequencies are related to TM101, TM103, TM105, and TM115.

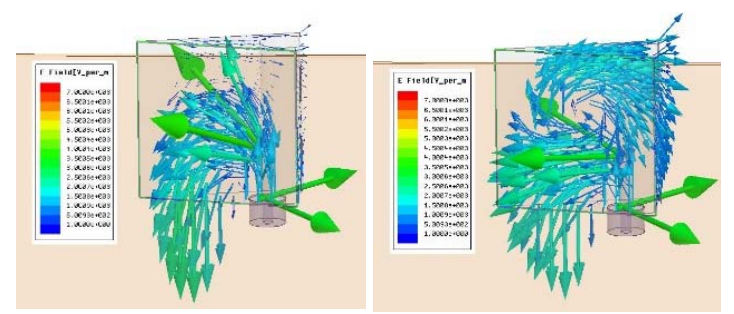

(A)

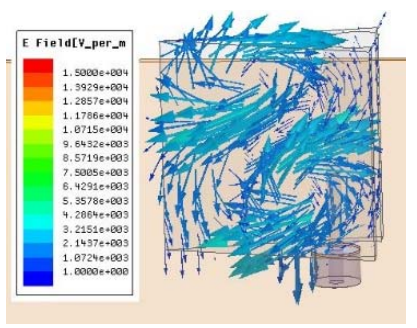

(C)
(B)

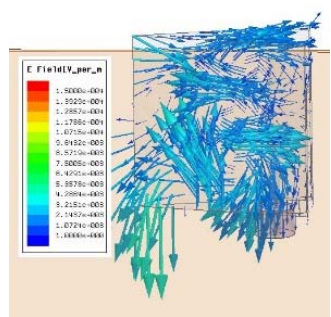

(D)
Fig. 6. Electric field patterns at A. $6.2 \mathrm{GHz}$, B. $7.2 \mathrm{GHz}$, C. $11.4 \mathrm{GHz}$, and D. $11.8 \mathrm{GHz}$ 
In many papers such as [15] and [16], the effect of hole or arrays of holes in DRA antennas was investigated. Using the hole can improve impedance bandwidth by reducing the quality factor of the antenna. In this paper, an embedded semicylindrical hole has been optimized to overcome the inappropriate values of the gain in the middle of the bandwidth $(7.5-10.7 \mathrm{GHz})$. Figures $3 \mathrm{~A}$, and $4 \mathrm{~A}$ show that increasing the hole diameter, as well as, movement of the hole to the center of TDRA lead to less quality factor, and better gain chart, but it disturbs the return loss at these frequencies.

In figure $2 \mathrm{~A}$, the reflection coefficient of the conventional TDRA has two resonances around $9 \mathrm{GHz}$. The first resonance is activated by monopole, and the second one is caused by TDRA. Decreasing of $b$ activate two resonant frequencies which are coincided, in the frequency range that gain values are significantly inappropriate. Using hole inside DRA inherently enhances return loss, so we should find a way to improve gain chart concurrently. Figure 7A shows the E-field vectors of conventional TDRA at $10.3 \mathrm{GHz}$. This figure shows that E-field vectors are not generally in the same direction. It can be observed that many of E-field vectors are parallel to ground plane or have a significant horizontal component. The effect of such pattern for E-field vectors is canceled by the effect of conducting ground plane. Consequently, it decreases antenna gain. Figure $7 \mathrm{~B}$ shows the E-field vectors of the proposed antenna at the same frequency. In this figure, it can be clearly seen that the E-field vectors are mostly in the vertical direction or have a significant vertical component, so they aimed to better gain value. Figure $8 \mathrm{~A}, 8 \mathrm{~B}$ show the radiation pattern of TDRA at $10.3 \mathrm{GHz}$ for conventional TDRA in comparison with the proposed antenna.

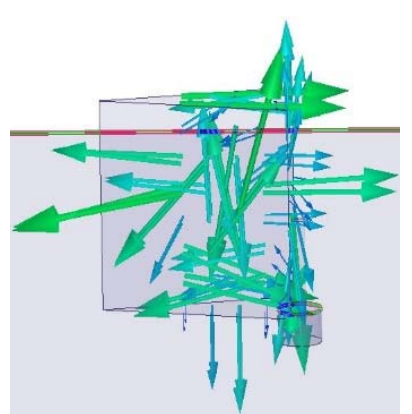

(A)

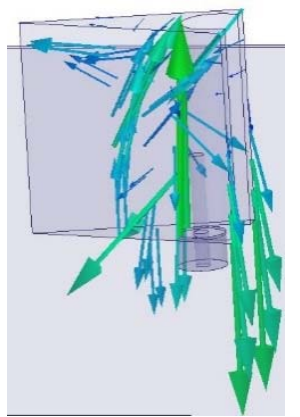

(B)
Fig. 7. Electric field patterns at $10.3 \mathrm{GHz}$ for A. conventional TDRA, B. the proposed antenna

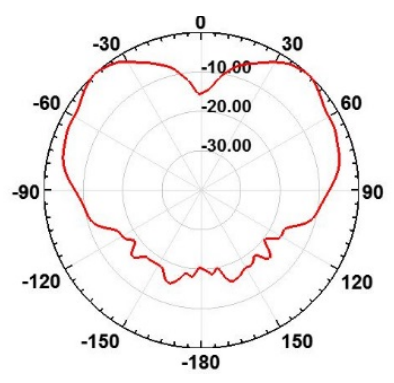

(A)

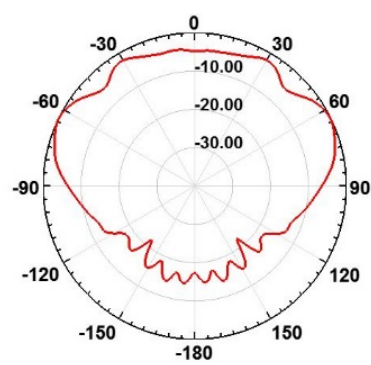

(B)
Fig. 8. Radiation patterns at $10.3 \mathrm{GHz}$ for A. conventional TDRA, B. the proposed antenna
TABLE II. GAIN, AND BANDWIDTH, OF REFERENCED TDRAs COMPARE WITH THE PROPOSED ANTENNA

\begin{tabular}{c|cccc}
\hline $\begin{array}{c}\text { Ref. } \\
\text { No. }\end{array}$ & gain & Frequency range & $\boldsymbol{B W}$ & Permittivity \\
\hline$[7]$ & $\mathbf{d B i}$ & $\boldsymbol{G H z}$ & $\%$ & \\
\hline$[8]$ & - & $4.33-7.02$ & 47.4 & 10 \\
{$[9]$} & Max: 6.12 & $2.34-2.97$ & 23.5 & 10 \\
\hline$[10]$ & - & $9.27-11.67$ & 22.9 & 9.8 \\
\hline 11$]$ & $3.5-4.76$ & $4.8-7.0$ & 37 & 12 \\
{$[12]$} & Max: 5.04 & $6.74-9.74$ & 33 & $10,12.4,16$ \\
\hline$[13]$ & Max: 7.98 & $4.0-6.02$ & 41 & 9.8 \\
\hline$[14]$ & - & $2.0-3.0$ & 40 & 12 \\
\hline$[15]$ & - & $3.0-6.3$ & 71 & 9.8 \\
\hline $\begin{array}{c}\text { Proposed } \\
\text { antenna }\end{array}$ & $1.6-7.2$ & $5.29-12.35$ & 80 & 10 \\
\hline
\end{tabular}

Table 2 shows the gain and the bandwidth of referenced antennas compare with the proposed antenna. The table shows that the proposed antenna has a good gain and excellent impedance bandwidth. The radiation pattern is also stable in the whole bandwidth.

\section{CONCLUSION}

In this paper, a TDRA with a drilled cylindrical hole at the small side of the triangle is proposed. Using this hole could improve impedance bandwidth by reducing quality factor. Results of conventional TDRA show that gain chart in the middle of the bandwidth is not appropriate. Therefore, location and dimensions of the hole are optimized so that gain chart was improved and stabilized. Using this technique collimates E-field vectors in the vertical direction and improves gain chart, as well as, impedance bandwidth. In the proposed antenna, a bandwidth of $80 \%(5.29 \mathrm{GHz}-12.35$ $\mathrm{GHz})$ and gain variation of $(1.6 \mathrm{dBi}-7.2 \mathrm{dBi})$ has been achieved.

\section{REFERENCES}

[1] M. Khalily, M.K.A Rahim, and A.A. Kishk, "Bandwidth Enhancement and Radiation Characteristics Improvement of Rectangular Dielectric Resonator Antenna", IEEE Antennas and Wireless Propagation Letters, Vol. 10, 2011, pp. 393-395

[2] M. Khalily, M.K.A. Rahim, N.A. Murad, N. A. Samsuri, and A.A. Kishk, "Rectangular Ring-shaped Dielectric Resonator Antenna for Dual and Wideband Frequency", Microwave and Optical Technology Letters, Vol. 55, No. 5, May 2013, pp. 1077-1081

[3] N.M. Nor, M.H. Jamaluddin, M.R. Kamarudin, and M. Khalily, "Rectangular Dielectric Resonator Antenna Array for $28 \mathrm{GHz}$ Applications", Progress In Electromagnetics Research C, Vol. 63, 2016, pp. 53-61

[4] S. Danesh, S.K.A. Rahim, and M. Khalily, "04. A Wideband Trapezoidal Dielectric Resonator Antenna with Circular Polarization", Progress In Electromagnetics Research Letters, Vol. 34, 2012, pp. 91100

[5] M. Khalily, M.R. Kamarudin, M.H. Jamaluddin, "A Novel Square Dielectric Resonator Antenna With Two Unequal Inclined Slits for Wideband Circular Polarization", IEEE Antennas and Wireless Propagation Letters, Vol. 12, 2013, pp. 1256-1259

[6] M. Khalily, M.K.A. Rahim, and A.A. Kishk, "Planar Wideband Circularly Polarized Antenna Design with Rectangular Ring Dielectric 
Resonator and Parasitic Printed Loops", IEEE Antennas and Wireless Propagation Letters, Vol. 11, 2012, pp. 905-908

[7] S. Maity and B. Gupta, "Experimental Investigations on Wideband Triangular Dielectric ResonatorAntenna", IEEE Transactions on Antennas and Propagation, 2016, Vol. 64, Iss.12, pp. 5483-5486

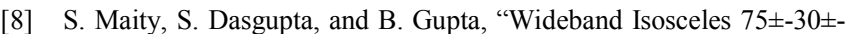
$75 \pm$ Triangular Dielectric Resonator Antenna", Progress In Electromagnetics Research Symposium Proceedings, KL, MALAYSIA, March 27-30, 2012, pp. 1109-1112

[9] Sudipta Maity, "Hybrid Triangular Dielectric Resonator Antenna (DRA) for WLAN/ISM Application”, Indian Antenna Week (IAW), 2011 , pp. 1 - 4

[10] A. Gupta1, R.K. Gangwar, S. P. Singh, "Three element dual segment triangular dielectric resonator antenna for X-band applications", Progress In Electromagnetics Research C, 2013, Vol. 34, pp. 139-150

[11] R.K. Gangwar, P. Ranjan, A. Aigal, "Four element triangular dielectric resonator antenna for wireless application", International Journal of Microwave and Wireless Technologies, 2015, pp. 1-7

[12] F. Khatoon, A. Kumar, N. Vats, "Stack of Four Elements Triangular Dielectric Resonator Antenna Excited by Coaxial Probe", International Journal of Emerging Technology and Advanced Engineering, 2014, Vol. 4, Iss. 5, P. 287-290

[13] R. Kumari, K. Parmar and S.K. Behera, "Conformal Patch Fed Stacked Triangular Dielectric Resonator Antenna for WLAN Applications", INTERACT-2010, 2010, pp. 104 - 107

[14] A.A. Kishk, "Tetrahedron and Triangular Dielectric Resonator Antenna with Wideband Performance", IEEE Antennas and Propagation Society International Symposium, 2002, Vol. 4, pp. 462465

[15] N.R. Nayak, D.R. Saini, R.K. Singh, D. Sankaranarayanan, D.V. Kiran, B. Mukherjee, "Edge Grounding Perforated Triangular Dielectric Resonator Antenna", URSI Asia-Pacific Radio Science Conference (URSI AP-RASC), 2016, pp. 1805-1807

[16] T.H. Chang, Y.C. Huang, W.F. Su, J.F. Kiang, "Wideband Dielectric Resonator Antenna With a Tunnel", IEEE Antennas and Wireless Propagation Letters, 2008, Vol. 7 